\title{
Synthesis of Cyclohexanone Pentaerythritol Ketal Catalyzed by Sulfonated Zeolite
}

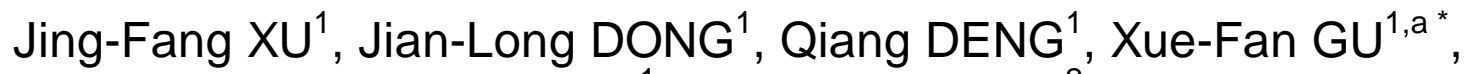 \\ Ying TANG ${ }^{1}$, Zhi-Fang ZHANG ${ }^{2}$ \\ ${ }^{1}$ College of Chemistry and Chemical Engineering, Xi'an Shiyou University, Xi'an 710065, China \\ ${ }^{2}$ School of Chemistry and Chemical Engineering, Yulin University, Yulin 719000, China \\ axuefangu@xsyu.edu.cn \\ ${ }^{*}$ Corresponding author
}

Keywords: Cyclohexanone Pentaerythritol Ketal, X-Ray Structure, Thermal Character.

\begin{abstract}
In the previous research, it has been found that cyclohexanone pentaerythritol ketal has some bioactivity in the treatment of hurt in sports. In this work, cyclohexanone pentaerythritol ketal was synthesized from cyclohexanone and pentaerythritol by condensation catalyzed by zeolite and modified zeolite, and the reaction condition was discussed. It was characterized by NMR, MS spectrum and single-crystal X-ray diffraction. It crystallizes in orthorhombic space group, P21, with a unit cell dimensions of $\mathrm{a}=11.1214(9) \AA, \mathrm{b}=13.9216(6) \AA$ and $\mathrm{c}=11.6658(10) \AA$. There are two molecules with different conformation in the crystal, varying from bond lengths to angles. The stacking interaction is responsible for the crystal's 1-D supra-molecular structure.
\end{abstract}

\section{Introduction}

In the synthesis chemistry, acetals/ketals are important in synthetic carbohydrate and steroid chemistry $[1,2]$. Acetonide formation is the commonly used protection for 1, 2-(cis)- and 1,3-diols, which have extensively been used in carbohydrate chemistry to selectively mask the hydroxyls of different sugars. Besides the interest of acetals/ketals as protecting groups, they are used both as intermediates and as end products, in the phyto pharmaceutical, fragrances and lacquers industries $[3,4]$. They have found direct applications as solvents in fragrance industries, cosmetics, food and beverage additives, pharmaceuticals, the synthesis of enantiomerically pure compounds, detergent and lacquer industries, and polymer chemistry [5-10]. Acetals have been also used in motor oils, lubricating oils, and hydraulic fluids and as an invert-emulsion for drilling petroleum operations [11].

In the previous research, it has been found that cyclohexanone pentaerythritol ketal has some bioactivity in the treatment of hurt in sports. Besides, pentaerythritol acetals in general are applied as plasticizers and vulcanizers, as physiologically active substance, potential protective groups for aldehydes and ketones, as raw materials for production of valuable resins and lacquers, as physiologically active substances [12]. In this article, we synthesized cyclohexanone pentaerythritol ketal (shown in Scheme 1) and determined its crystal structure by single-crystal X-ray.

\section{Experimental}

\section{Materials}

Chemicals were either prepared in our laboratories or purchased from Merck, Fluka and Aldrich Chemical Companies. All yields refer to isolated products. The products were characterized by comparison of their physical data with those of known samples or by their spectral data. NMR spectrum was recorded in the stated solutions, on a Bruker Drx-400 spectrometer, operating at $400 \mathrm{MHz}$ for $1 \mathrm{H} ; \delta$ values are reported in ppm and $\mathbf{J}$ values in hertz. Mass spectrum were recorded on a Micromass Platform II spectrometer, using the direct-inlet system operating in the electron impact (EI) mode at $75 \mathrm{eV}$. 
All $\mathrm{H}$ atoms were positioned geometrically, with $\mathrm{C}-\mathrm{H}=0.93-0.98 \AA$, and refined with a riding model, with $\operatorname{Uiso}(\mathrm{H})=1.2 \mathrm{Ueq}$ (carrier).

\section{Synthesis of Cyclohexanone Pentaerythritol Ketal}

The reaction is described in Scheme 1. Cyclohexanone and pentaerythritol were added in a flask with the molar ratio of 2:1, and the toluene was added as the water carrier and the solvent. 5\%(wt) solid acid, catalyst was added as catalyst. The mixture was refluxed until no water can be carried out, and the cool to room temperature. The catalyst was filtrated, and the solvent was evaporated to produce the crude product. Colorless crystals of cyclohexanone pentaerythritol ketal were obtained in ethanol by recrystallization. Mp 115.5-116.2 ${ }^{\circ} \mathrm{C}$; $1 \mathrm{H}-\mathrm{NMR}$ (D6-DMSO, $\left.400 \mathrm{MHz}\right), \delta: 3.62(4 \mathrm{H}, \mathrm{s}), 1.76(4 \mathrm{H}, \mathrm{t}, J=$ $7.2 \mathrm{~Hz}), 1.55(4 \mathrm{H}, \mathrm{td}, J=7.6,1.2 \mathrm{~Hz}), 1.35(2 \mathrm{H}, \mathrm{t}, J=7.6 \mathrm{~Hz})$; MS (EI) $m / z: 296\left(\mathrm{M}^{+}\right)$.

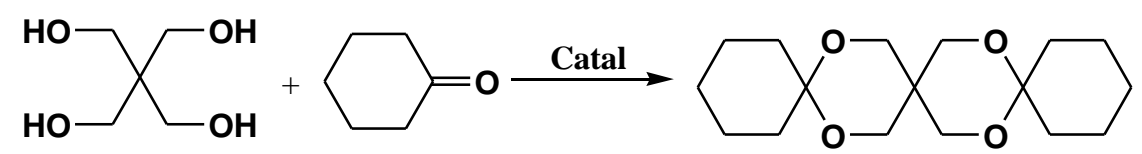

Scheme 1 Synthesis of cyclohexanone pentaerythritol ketal

\section{Results and Discussion}

\section{Synthesis}

In this synthesis, three kinds of zeolite and corresponding sulfonated species were screened, and the results were shown in Fig. 1. From the results, it can be found that the catalytic activity is quite different. For the zeolite, NaY and ZSM-5 are active for this reaction, and ZSM-5 is the most effective one with the yield of $86.3 \%$, compared with $5.9 \%$ for $4 \mathrm{~A}$. After the sulfonation, all the yields are increased. The yield of cyclohexanone pentaerythritol ketal increases to $98.1 \%, 96.1 \%$ and $37.5 \%$ respectively, which may be due to the increased acidity by sulfonation.

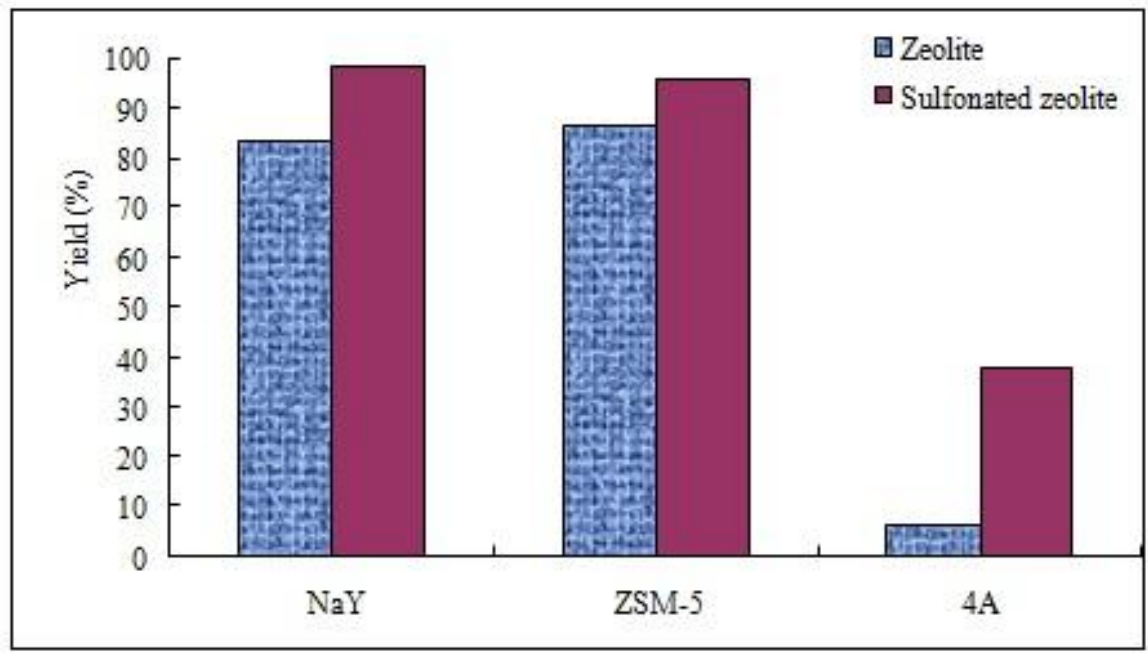

Fig. 1 The yield of cyclohexanone pentaerythritol ketal catalyzed by zeolite

In the following work, the effect of the dosage of ZSM-5 on the yield of cyclohexanone pentaerythritol ketal was investigated by using varying the dosage from $1 \%$ to $20 \%$, and the results was shown in Fig. 2. From the results, it can be found that it can be seen that the low amount of catalyst is not efficient to cause the reaction happen. With increasing the amount to $22 \%$, yield of cyclohexanone pentaerythritol ketal increases up to $96.1 \%$. The reason for the increase conversion with an increase in the catalyst weight should be attributed to the increase number of catalytically active sites provided by large amount of ZSM-5. Further increase the amount of catalyst to $20 \%$ the yield does not increase further. 


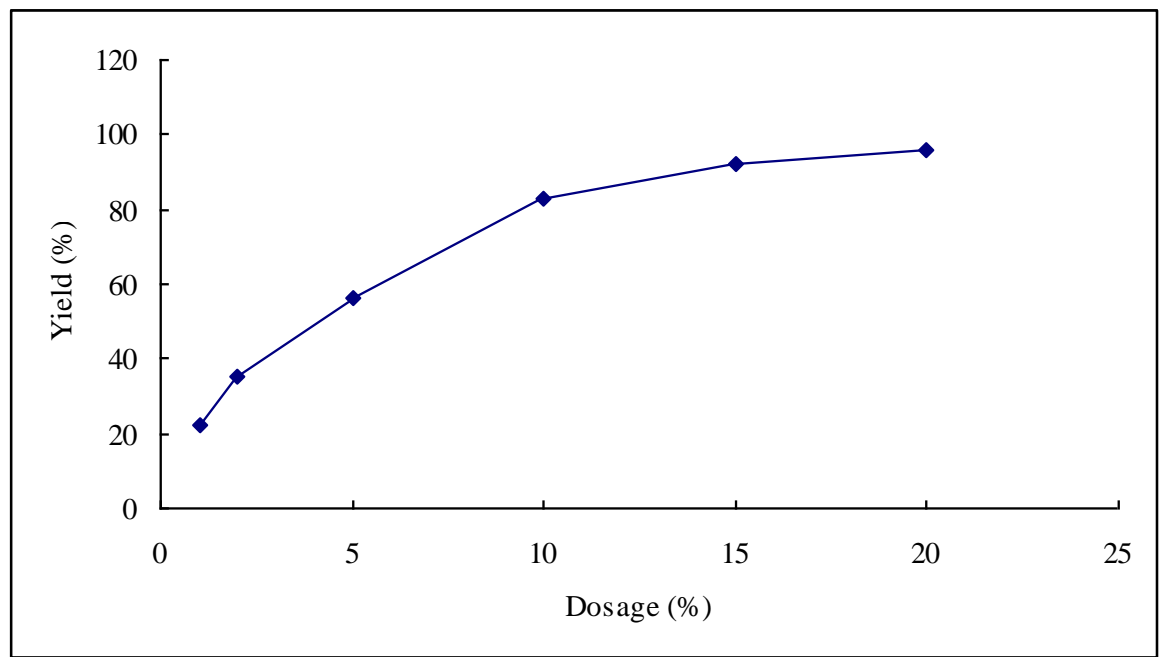

Fig. 2 The effect of the dosage of ZSM-5 on the yield of cyclohexanone pentaerythritol ketal

\section{Structure}

The stereo structure of the title compound was corroborated by X-ray diffraction analysis. The molecular structure is shown in Fig. 3, the unit cell is shown in Fig. 4, and the packing of the compounds is depicted in Fig. 5, which were drawn with ORTEP-3. The X-ray structural determination of the title compound confirmed the assignment of its structure from NMR and MS spectra data. Geometric parameters of the title crystal structure are in the usual ranges. There are two in dependent molecules with different conformation in the crystal, varying in bond lengths and angles. It crystallizes in crystallizes in the triclinic space group, $\mathrm{P} 21$, with unit cell dimensions $\mathrm{a}=11.1214(9) \AA, \mathrm{b}=13.9216(6) \AA$ and $\mathrm{c}=$ $11.6658(10) \AA$.

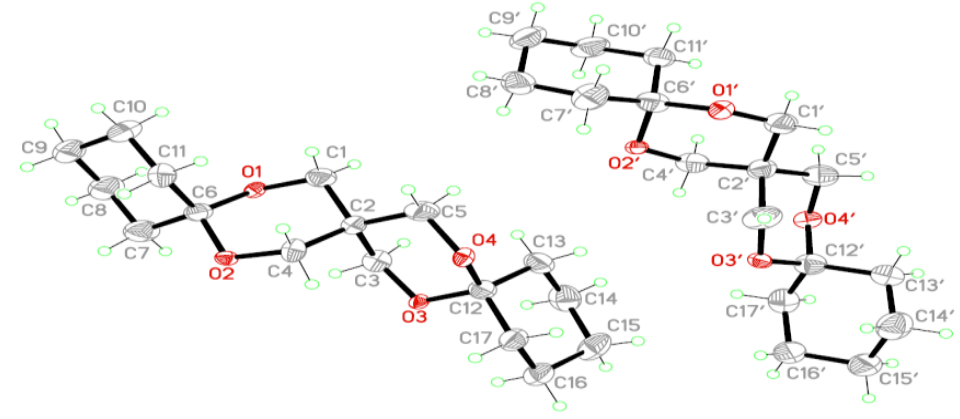

Fig. 3 The molecular structure of cyclohexanone pentaerythritol ketal

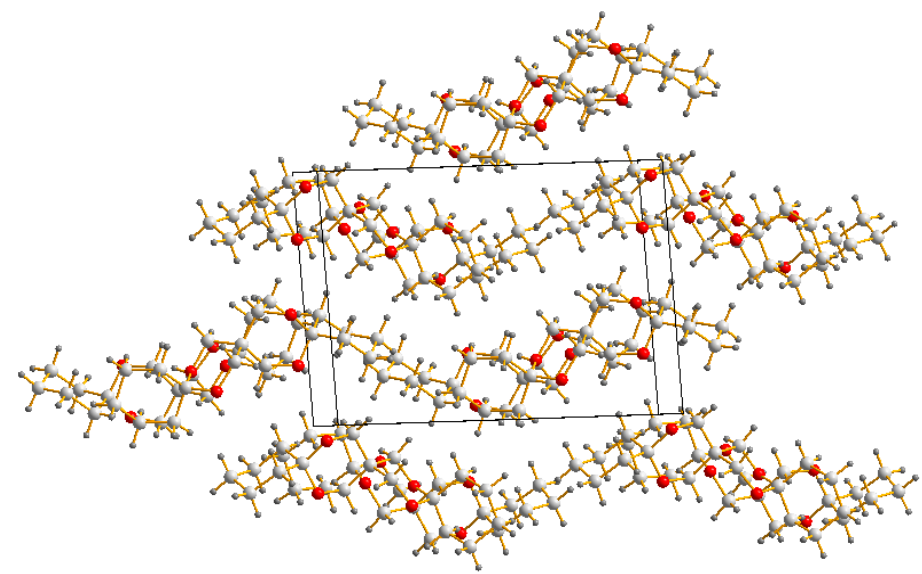

Fig. 4 The unit cell of cyclohexanone pentaerythritol ketal 


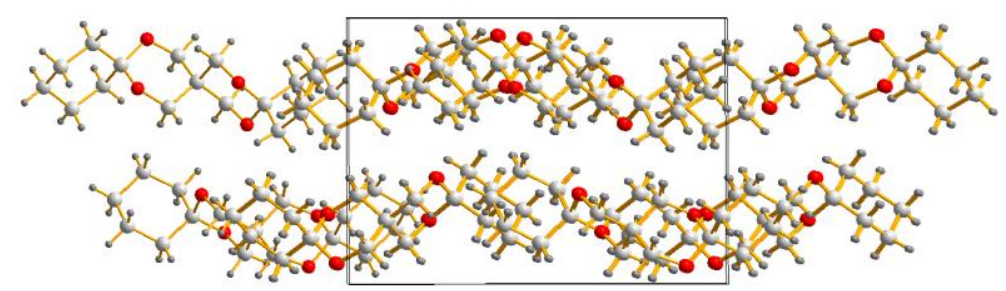

Fig. 5 The $1 \mathrm{D}$ and 2D packing diagram of cyclohexanone pentaerythritol ketal

There are two independent molecules with different conformation in the crystal, varying in bond lengths and angles as shown in Fig. 3. For example, the lengths of the main $\mathrm{C}-\mathrm{O}$ bonds, $\mathrm{C} 1-\mathrm{O} 1, \mathrm{C} 4-\mathrm{O} 2$, C3-O3, and C5-O4 are 1.430, 1.425, 1.429, and $1.421 \AA$ respectively, while, in the other molecular, the lengths of the main C-O bonds, C1'-O1', C4'-O2', C3'-O3', and C5'-O4' are 1.429, 1.417, 1.412, and $1.425 \AA$ respectively. The main angles of C-O-O bonds, $\angle \mathrm{C} 1-\mathrm{O} 1-\mathrm{C} 6, \angle \mathrm{C} 4-\mathrm{O} 2-\mathrm{C} 6, \angle \mathrm{C} 3-\mathrm{O} 3-\mathrm{C} 12$, and $\angle \mathrm{C} 5-\mathrm{O} 4-\mathrm{C} 12$, are $114.4,114.5,114.2$, and 113.4 respectively, while, in the other molecular, the main angles of C'-O'-O' bonds, $\angle \mathrm{C} 1$ '-O1'-C6', $\angle \mathrm{C} 4$ '-O2'-C6', $\angle \mathrm{C} 3$ '-O3'-C12', and $\angle \mathrm{C} 5$ '-O4'-C12', are $113.4,114.3,115.1$, and $114.4^{\circ}$ respectively. There are three quaternary carbons in each molecular. The bonds length related to $\mathrm{C} 2$ are very similar in the range from $1.518 \AA$ to $1.532 \AA$, and the related angels are from 107.0 to $111.0^{\circ}$, which should be due to the symmetry center role of $\mathrm{C} 2$. For other two quaternary carbons, $\mathrm{C} 6$ and $\mathrm{C} 12$, the related bonds length and the angle are in wider ranges.

\section{Electronic Spectra}

Electronic spectra of cyclohexanone pentaerythritol ketal in methanol solution was presented in Fig. 6 . In the spectra, the compound exhibits two intra-ligand charge transfer bands at $208 \mathrm{~nm}$ (high energy) and at $275 \mathrm{~nm}$ (low energy), which is probably due to the electronic transfer from ground state to the excited state.

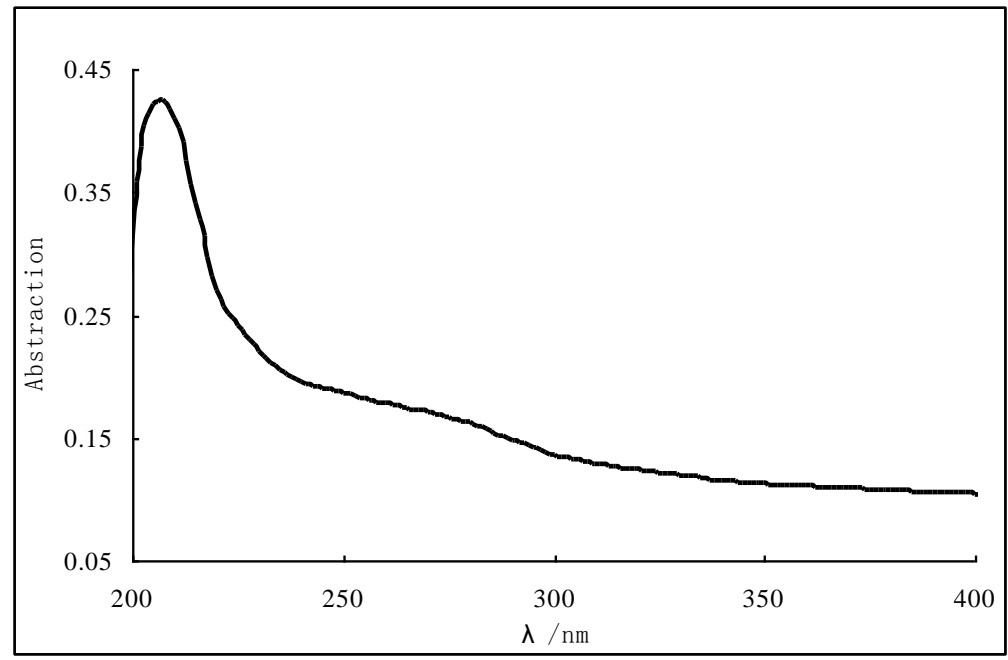

Fig. 6 The electronic spectra of cyclohexanone pentaerythritol ketal

\section{Conclusion}

In This work, the synthesis and structure of cyclohexanone pentaerythritol ketal has been studied. The reaction conditions were screened and the structure was determined by d single-crystal X-ray diffraction. It crystallizes in orthorhombic space group, $\mathrm{P} 21$, with a unit cell dimensions of $\mathrm{a}=11.1214(9) \AA, \mathrm{b}=$ 13.9216(6) $\AA$ and $\mathrm{c}=11.6658(10) \AA$. There are two molecules with different conformation in the crystal, varying from bond lengths to angles. The stacking interaction is responsible for the crystal's 1-D supra-molecular structure. 


\section{Acknowledgement}

This research was financially supported by the grants from Collaborative Innovation \& Local Serving Plan in Shaanxi Province (No.15JF035) and Key Lab Scientific Research Program Funded by Shaanxi Provincial Education Department (No. 16JS094).

\section{References}

[1] M.J. Climent, A. Velty, A. Corma, Design of a solid catalyst for the synthesis of a molecule with blossom orange scent, Green Chem. 4 (2002) 565-569.

[2] K. Bauer, D. Garbe, H. Surburg, Common Fragrances and Flavour Materials, 2nd ed., VCH: New York, 1990.

[3] M. Clode, Carbohydrate cyclic acetal formation and migration, Chem. Rev. 79 (1979) 491-513.

[4] S.V. Ley, H.W.M. Priepke, Eintopfsynthese einer trisaccharideinheit des gemeinen polysaccharid-antigens von Streptococci der Gruppe B unter verwendung cyclohexan-1,2-diacetal[CDA]-geschützter rhamnoside, Angew. Chem. 106 (1994) 2412-2414.

[5] K. Bruns, J. Conard, A. Steigel, Stereochemistry of cyclic compounds-I: Synthesis and conhgurational assignment of diawereomeric 2,4-dioxaspir[5.5] undec-8-enes, Tetrahedran, 35 (1979) 2523-2527.

[6] M.K. Cheung, N.L. Douglas, B. Hinzen, S.V. Ley, X. Pannecoucke, One-pot synthesis of tetra- and pentasaccharides from monomeric building blocks using the principles of orthogonality and reactivity tuning, Synlett, 3 (1997) 257-260.

[7] K. Narasaka, M. Inone, T. Yamada, J. Sugiomori, N. Iwasawa, Asymmetric diels-alder reaction by the use of a chiral titanium catalyst with molecular sieves 4A. Remarkable solvent effect on the enantioselectivity, Chem. Lett. (1987) 2409-2412.

[8] J. Elliot, 1,3-Dioxalane Polymers in Comprehensive Heterocyclic Polymers1,3-Dioxalane Polymers in Comprehensive Heterocyclic Polymers, Pergamon Press: Oxaford, UK, 1984.

[9] M .Hille, H. Wittkus, H. J. Scholz, F. Weimlet, Use of acetals, U.S. Patent 5,759,963 (1998).

[10] A.O. Barros, A.T. Faisca, E.R. Latcher, R.S.V. Nascimento, R.A.S. Gil, Acetalization of hexanal with 2-ethyl hexanol catalyzed by solid acids, J. Braz. Chem. Soc. 22 (2011) 359-363.

[11]BR. Jermy, A. Pandurangan, Al-MCM-41 as an efficient heterogeneous catalyst in the acetalization of cyclohexanone with methanol, ethylene glycol and pentaerythritol, J Mol Catal A-Chem. 256, (2006) 184-192.

[12]T.F. Parangi, B.N. Wani, U.V. Chudasama, Acetalization of Carbonyl Compounds with Pentaerythritol Catalyzed by Metal(IV) Phosphates as Solid Acid Catalysts, Ind. Eng. Chem. Res. 52 (2013) 8969-8977. 